\title{
Highlight of primary and secondary relaxations in amorphous stereocomplex polylactides
}

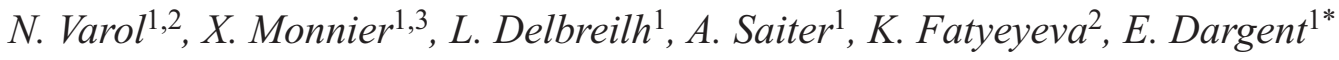 \\ ${ }^{1}$ Normandie Univ, UNIROUEN, INSA Rouen, CNRS, GPM Groupe de Physique des Materiaux, 76000 Rouen, France \\ ${ }^{2}$ Normandie Univ, UNIROUEN, INSA Rouen, CNRS, PBS Polymeres Biopolymeres Surfaces, 76000 Rouen, France \\ ${ }^{3}$ Donostia, International Physics Center (DIPC), Paseo Manuel de Lardizabal 4, 20018 San Sebastian, Spain
}

Received 10 May 2019; accepted in revised form 17 July 2019

\begin{abstract}
A racemic mixture of two stereoregular polylactides (PLAs) (i.e. PLLA and PDLA) allows obtaining wholly amorphous stereocomplex PLA films by solvent casting method. The amorphous phase behavior of stereocomplex PLA is compared with that of PLLA and PDLA by advanced thermal analysis, such as Fast Scanning Calorimetry (FSC) and Dielectric Relaxation Spectroscopy (DRS). FSC allows us to quench at very high cooling rate (up to $4000 \mathrm{~K} \cdot \mathrm{s}^{-1}$ ) the studied polymers and to obtain glassy amorphous phases with high excess of enthalpy. It is shown that stereocomplexation has no influence on the glass transition temperature, the physical aging and on the cooperativity. The $\alpha$ and $\beta$ processes were examined to study the dielectric properties, such as relaxation time, dielectric strength, and fragility. The results of FSC and DRS are correlated to determine the values of cooperativity length which are found to be similar in a wide temperature range. It is found that the studied polymers have the similar dielectric properties independently on their tacticity.
\end{abstract}

Keywords: biopolymers, thermal properties, polylactic acid, amorphous phase, stereocomplex polymers

\section{Introduction}

When the interactions between the polymers with different tacticities and configurations predominate over those with the same tacticity and configuration, a stereoselective association takes place, which is called stereocomplexation or stereocomplex formation. Such a stereoselective interaction between polymers can be obtained by hydrogen bonds backbonding [1]. Well-known examples of stereocomplexation were reported for polymers with different tacticities and for enantiomeric polymers [2,3]. Stereocomplex formation between enantiomeric polymers leads to better physical properties than those of pure components [4]. As biodegradable, biosourced and biocompatible materials, poly(lactides) (PLAs) have the highest consumption to replace classical petroleum-based polymer materials in a wide-range of applications, i.e. packaging and biomedical devices $[5,6]$. The presence of chiral carbons in the skeletal chain of PLA yields to two stereoregular enantiomers, so called poly(L-lactide) (PLLA) and poly(D-lactide) (PDLA), allowing formation of stereocomplex PLA, which takes place depending on $\mathrm{CH}_{3} \ldots \mathrm{C}=\mathrm{O}$ interactions of stereoselective van der Waals forces [7]. Stereocomplex PLA has better properties than those of homopolymers, namely a melting temperature of $50^{\circ} \mathrm{C}$ higher than that of PLLA and PDLA [8, 9], and higher mechanical properties than PLLA and/or PDLA [10]. Equimolar PLLA and PDLA mixture in blend is favored to form pure sterecomplex crystals without fraction of homocrystals of either PLLA or PDLA [9]. The crystalline morphologies of pure stereocomplex PLA crystals, in equal and different mixing ratios, and the significant impact of stereocomplexation on crystalline phase were extensively studied in recent years [6, 8-14]. However, the 
amorphous phase behavior of stereocomplex PLA in the terms of vitrification kinetics and molecular mobility in the glassy and liquid-like state are still an enigmatic question. How the chirality of the stereocomplex structure in stereocomplex PLA influences the amorphous phase? This is an important question as a lot of polymer properties depend on the amorphous phase. By example, the mechanical and the gas transport properties which are of prime importance for packaging applications are directly related to the crystalline and amorphous phase properties. Transport properties are correlated with the possible interactions between permeant molecules and polymer chains, and with the existence of free volume and molecular mobility in the amorphous phase. Of course, crystalline phase morphology (i.e. size and pourcentage of crystals) is also important because crystals act as barriers to water and gas penetration. The passage of permeant molecules is resisted by the presence of the crystalline phase [15]. The crystalline zone present in the polymer may increase the effective pathlength of diffusion and also reduce the polymer chain mobility in the amorphous phase.

In order to compare the amorphous phase of stereocomplex and homopolymers PLAs, wholly amorphous samples were prepared in this work. It is decided to investigate in details the characteristic values of the glass transition phenomenon, the physical aging, and to determine the characteristic size of the cooperative motion which occurs at temperature close to the glass transition. When dealing with vitrification kinetics, the concept of fictive temperature $T_{\mathrm{f}}$ is preferable in comparison to the standard glass transition temperature $T_{\mathrm{g}}[16]$. The fictive temperature is thermodynamically defined as the intersection between the enthalpies of the glassy and the liquid-like states. $T_{\mathrm{f}}$ is usually measured on heating by differential scanning calorimetry (DSC) analysis and can be determined from the enthalpy overshoot by a method developed by Moynihan et al. [17]. This concept allows to characterize the cooling rate dependence of the glass transition as well as to investigate the structural relaxation. Indeed, after vitrification, even though the formed glass seems to be 'frozen' on the measurement time scale, molecular mobility still exists below the glass transition temperature $[18,19]$. Therefore, when the glass forming liquids are held below their respective glass transition temperatures, the structural relaxation occurs. Also called physical aging, this phenomenon is the spontaneous evolution of the non-equilibrium glass towards its thermodynamic equilibrium [19]. Since PLAs are polymers with a glass transition temperature around $60^{\circ} \mathrm{C}$, they are known to be susceptible to physical aging at ambient temperature [20].

At the same time, molecular mobility of the glass forming liquids, namely the segmental and/or local relaxations, is usually investigated through the relaxation time or the viscosity. From a spatial point of view, the cooperative character of the main relaxation process (called $\alpha$ ) is also described by the size of the cooperative rearranging region (CRR) [21]. Classical theories of the glass transition consider the growth of the dynamic correlation size as the cause of the slowed dynamics near the glass transition: increasing during cooling, the constitutive units cannot reorient or diffuse independently, so the motion of each constitutive unit depends on the neighboring motions. Thus, quantification of the correlations of the molecular motions along the glass transition is essential to characterize the motions in complex systems. This dynamic correlation size can be determined according to the Donth's approach, allowing us to estimate the number of structural units moving with neighbors, i.e. forming a CRR. In the past few years, few works have examined the influence of different physical or chemical structures on the molecular dynamics of PLA through the size of the CRR: presence of crystalline phases [22], pure geometric confinement [23, 24], plasticizers [20, 25], and nanofillers [26]. For example, it is shown that the introduction of plasticizer leads to decrease the CRR size due to a decrease of interchain bonds [27].

In this context, the present work aims to study the influence of the tacticity on the glassy dynamics of amorphous phase of stereocomplex PLA. To do this, stereocomplex PLA was compared to the 'parents' polymers - PLLA and PDLA. Two different experimental techniques were combined to investigate thermodynamics and dynamics: Fast Scanning Calorimetry (FSC) and Dielectric Relaxation Spectroscopy (DRS), respectively. Due to the large range of heating and cooling rates (from 0.1 to $10^{4} \mathrm{~K} \cdot \mathrm{s}^{-1}$ ), FSC allows quenching PLA and heating without any structural reorganization. FSC allows to reach, for a glassy polymer, the relaxation equilibrium in a reasonable experimental time [28]. On the other hand, DRS permits to characterize the dynamics of the molecular motions as a function of temperature and frequency. 


\section{Experimental part}

\subsection{Materials}

PLLA and PDLA pellets used were provided from Natureplast, France. PLLA has a negligible content of $D$-isomer. PDLA has a L-isomer content less than $0.5 \%$. The two polymers have a density of $1.25 \mathrm{~g} / \mathrm{cm}^{3}$, a glass transition temperature $T_{\mathrm{g}}$ of $60^{\circ} \mathrm{C}$ and a melting temperature $T_{\mathrm{m}}$ of $175^{\circ} \mathrm{C}$. A weight average molecular weight $\left(M_{\mathrm{w}}\right)$ and polydispersity index determined by GPC analysis are 97 and $1.84 \mathrm{kDa}$ for PLLA and 99 and $1.79 \mathrm{kDa}$ for PDLA, respectively. PLLA and PDLA pellets were dried at $T=55^{\circ} \mathrm{C}$ during 3 days before use.

\subsection{Preparation of stereocomplex PLA}

In this work, stereocomplex PLA is called PLLA/ PDLA. The films were prepared by solution casting using chloroform. Ratio of PLLA to PDLA in films was maintained at $1: 1$ by weight with the polymer concentration of $3 \mathrm{~g} / \mathrm{dl}$. PLLA and PDLA pellets were dissolved in chloroform separately at the temperature of $25^{\circ} \mathrm{C}$. Then, PLLA and PDLA solutions were admixed under vigorous stirring for additional $1 \mathrm{~h}$. The prepared solutions were poured onto glass Petri dish to obtain free standing films. The solvent was allowed to evaporate at room temperature for $48 \mathrm{~h}$ under hood and the samples were further dried in oven at $120^{\circ} \mathrm{C}$ for $12 \mathrm{~h}$ to remove the solvent completely. Obtained PLLA/PDLA films have only stereocomplex crystals with a melting temperature $T_{\mathrm{m}}$ of $235^{\circ} \mathrm{C}$. For comparison, the pure homopolymer (PLLA and PDLA) films were prepared following the same preparation method.

\subsection{Quenched amorphous films}

Amorphous films were obtained by compression molding. Homopolymers (PLLA and PDLA) and PLLA/PDLA films were thermo-molded at the temperature of 180 and $230^{\circ} \mathrm{C}$, respectively, with a pressure of 1 bar between two hot plates during 5 min by using a manual hydraulic press ATLAS ${ }^{\mathrm{TM}}$ SPECAC. The temperatures were selected to be as close as possible to the equilibrium melting temperatures $T_{\mathrm{m}}^{0}$, which are 175 and $235^{\circ} \mathrm{C}$ for homocrystals $(\alpha)$ and stereocomplex (sc) crystals, respectively [14]. The thickness of the obtained films was $150 \pm 20 \mu \mathrm{m}$. The samples were then rapidly quenched in liquid nitrogen.

\subsection{Fast Scanning Calorimetry (FSC)}

FSC analysis was performed by fast scanning calorimeter Flash DSC 1 from Mettler Toledo. The power compensation twin-type calorimetric chip was used. Before use, these chip sensors were conditioned and corrected according to Mettler Toledo procedures. Small pieces of films were cut and placed at the center of the measurement area of a MultiSTAR UFS 1 MEMS chip sensors. A Huber TC100 intra cooler was used to cool the system down to $-90^{\circ} \mathrm{C}$ and carry out high cooling rates. The calorimeter was operated under nitrogen gas flow of $20 \mathrm{ml} \cdot \mathrm{min}^{-1}$ to avoid water condensation from the environment, and to optimize the temperature program applied [29]. The sample masses were estimated to be $45 \pm 3$ ng for PLLA, PDLA and PLLA/PDLA. The value was determined from the amplitude of the heat capacity step at the glass transition by comparing the value of the heat capacity step $\left(\Delta C_{\mathrm{P}}\right)$ obtained by DSC at $\left|\beta_{\mathrm{c}}\right|=\beta_{\mathrm{h}}=$ $0.78 \mathrm{~K} \cdot \mathrm{s}^{-1}\left(10 \mathrm{~K} \cdot \mathrm{min}^{-1}\right)$ and the value of $\Delta C_{\mathrm{P}}$ obtained by FSC at $\left|\beta_{\mathrm{c}}\right|=\beta_{\mathrm{h}}=1500 \mathrm{~K} \cdot \mathrm{s}^{-1}$ [28]. The heat flow hereby was normalized to the mass and the scanning rate, and the spectra curves were then expressed in equivalent $C_{\mathrm{P}}$ unit, i.e. $\mathrm{J} \cdot \mathrm{K}^{-1} \cdot \mathrm{g}^{-1}$. The thermal lag $\left(\delta T_{\mathrm{L}}\right)$ caused by the sample thickness was determined for each sample. Two corrections were applied as proposed by Schawe [30], namely the static $\left(\delta T_{S}\right)$ and the dynamic $\left(\delta T_{\mathrm{D}}\right)$ thermal lag. $\delta T_{\mathrm{S}}$ corresponds to a third of the difference between the onset melting point of the indium piece placed on the sample specimen and the onset melting point of the indium piece placed directly on the reference chip sensor, when extrapolated to heating rate equal to zero. $\delta T_{\mathrm{D}}$ corresponds to a half of the difference between the glass transition temperatures $T_{\mathrm{g}}$ determined from measurements upon heating and cooling. A total thermal lag value was the sum of $\delta T_{\mathrm{S}}$ and $\delta T_{\mathrm{D}}$. Thermal histories of homopolymers (PLLA and PDLA) and PLLA/PDLA samples were erased at 220 and $270^{\circ} \mathrm{C}$, respectively, during $0.5 \mathrm{~s}$ before any investigation. Samples were then studied from -50 up to $270^{\circ} \mathrm{C}$ at scanning rates $\left|\beta_{\mathrm{c}}\right|=\beta_{\mathrm{h}}$ ranging from 300 up to $4000 \mathrm{~K} \cdot \mathrm{s}^{-1}$ to determine the glass transition temperatures. In this work, we determined the glass transition temperatures as limiting fictive temperatures by area-matching method proposed by Moynihan et al. [17]. The physical aging was performed at $T_{\text {ag }}=T_{\mathrm{g}}-5^{\circ} \mathrm{C}, T_{\mathrm{ag}}=T_{\mathrm{g}}-8^{\circ} \mathrm{C}, T_{\mathrm{ag}}=$ $T_{\mathrm{g}}-13^{\circ} \mathrm{C}$ and $T_{\mathrm{ag}}=T_{\mathrm{g}}-18{ }^{\circ} \mathrm{C}$ with aging times ranging from 0.001 up to $100 \mathrm{~min}$. 


\subsection{Dielectric Relaxation Spectroscopy (DRS)}

DRS measurements were carried out with a Novocontrol Alpha analyzer. The temperature was controlled by a Quatro Novocontrol Cryosystem with temperature stability better than $\pm 0.2 \mathrm{~K}$. Samples were placed between parallel electrodes, using $30 \mathrm{~mm}$ diameter inox plated electrodes. The broadband dielectric converter (alpha analyzer interface) allows the measurement of the complex dielectric permittivity (real and imaginary parts) in a frequency range from $2 \cdot 10^{6} \mathrm{~Hz}$ down to $0.1 \mathrm{~Hz}$. The temperature was changed between -150 and $110^{\circ} \mathrm{C}$ with increasing step of $10^{\circ} \mathrm{C}$ for the range from -150 up to $50^{\circ} \mathrm{C}$, and $1^{\circ} \mathrm{C}$ for the range from 50 up to $110^{\circ} \mathrm{C}$. During the whole measurement, the sample was kept in a pure nitrogen atmosphere.

The complex permittivity $\varepsilon^{*}$ signals associated with the $\alpha$-peaks were fitted by the empirical HavrilakNegami (HN) function (Equation (1)) to complete quantitative analysis of the dielectric spectra in the frequency domain [31].

$\varepsilon^{*}(\omega)=\varepsilon_{\infty}+\frac{\Delta \varepsilon}{\left[1+\left(i \omega \tau_{\mathrm{HN}}\right)^{\alpha_{\mathrm{HN}}}\right]^{\beta_{\mathrm{HN}}}}$

The HN function lets fitting the real $\varepsilon^{\prime}(\omega)$ and the imaginary components $\varepsilon^{\prime \prime}(\omega)$ of the complex dielectric permittivity $\varepsilon^{*}(\omega)$ by Equations (2) and (3):

$$
\begin{aligned}
& \varepsilon^{\prime}(\omega)=\varepsilon_{\infty}+ \\
& +\Delta \varepsilon_{\mathrm{HN}} \frac{\cos \left(\beta_{\mathrm{HN}} \varphi_{\mathrm{HN}}\right)}{\left[1+2 \sin \left(\frac{\pi\left(1-\alpha_{\mathrm{HN}}\right)}{2}\right)\left(\omega \tau_{\mathrm{HN}}\right)^{\alpha_{\mathrm{HN}}}+\left(\omega \tau_{\mathrm{HN}}\right)^{\left.2 \alpha_{\mathrm{HN}}\right]^{\beta_{\mathrm{HN}} / 2}}\right.}
\end{aligned}
$$

$$
\begin{aligned}
& \varepsilon^{\prime \prime}(\omega)= \\
& =\Delta \varepsilon_{\mathrm{HN}} \frac{\sin \left(\beta_{\mathrm{HN}} \varphi_{\mathrm{HN}}\right)}{\left[1+2 \sin \left(\frac{\pi\left(1-\alpha_{\mathrm{HN}}\right)}{2}\right)\left(\omega \tau_{\mathrm{HN}}\right)^{\alpha_{\mathrm{HN}}}+\left(\omega \tau_{\mathrm{HN}}\right)^{2 \alpha_{\mathrm{HN}}}\right]^{\beta_{\mathrm{HN}} / 2}}
\end{aligned}
$$

where $\omega$ is the angular position $(\omega=2 \pi f), \varepsilon_{\infty}$ is the unrelaxed dielectric permittivity, $\Delta \varepsilon_{\mathrm{HN}}$ is the relaxation strength, $\tau_{\mathrm{HN}}$ is a characteristic relaxation time and $\alpha_{\mathrm{HN}}$ and $\beta_{\mathrm{HN}}$ are shape parameters describing the symmetric and asymmetric broadening factor of the dielectric spectra, respectively. In order to improve the consistency of the fit results, the fitting has been carried out simultaneously for both real and imaginary parts of the complex signals.

\section{Results and discussion}

After a cooling from the melt at $\left|\beta_{\mathrm{c}}\right|=1500 \mathrm{~K} \cdot \mathrm{s}^{-1}$, the glass transition temperatures of the samples measured from heating at $\beta_{\mathrm{h}}=\left|\beta_{\mathrm{c}}\right|$ are $65 \pm 2,66 \pm 1$, $65 \pm 1^{\circ} \mathrm{C}$ for PLLA, PDLA and PLLA/PDLA films, respectively. It is well known that $T_{\mathrm{g}}$ depends on the glass formed, i.e. on the cooling rate applied to the material from the liquid-like state $[30,32,33]$. In order to form same glass by FSC and DSC, amorphous samples were vitrified using the same cooling rate as during DSC analysis, i.e. at $0.78 \mathrm{~K} \cdot \mathrm{s}^{-1}$. The glass transition temperatures of samples vitrified by cooling at $0.78 \mathrm{~K} \cdot \mathrm{s}^{-1}$ were investigated upon heating at the scanning rates ranged from 300 up to $4000 \mathrm{~K} \cdot \mathrm{s}^{-1}$. Due to the difference between cooling and heating rates, there is an endothermic peak superimposed to the glass transition as usually observed [17]. Thus, the glass transition temperature of samples is calculated by area matching method [30] in terms of the limiting fictive temperature and results are shown in Figure 1. The glass transition temperatures upon cooling were also calculated from the signal on conventional DSC as $56^{\circ} \mathrm{C}$ for PLLA and PDLA, and $54^{\circ} \mathrm{C}$ for PLLA/PDLA. These values are the same as the values of the corrected glass transition temperatures obtained from FSC during heating (Figure 1). As expected, the glass transition temperature depends on the applied cooling rate and is independent from the heating rate. The same cooling rate causes the unique glass transition temperature measured upon heating [32]. It should be mentioned

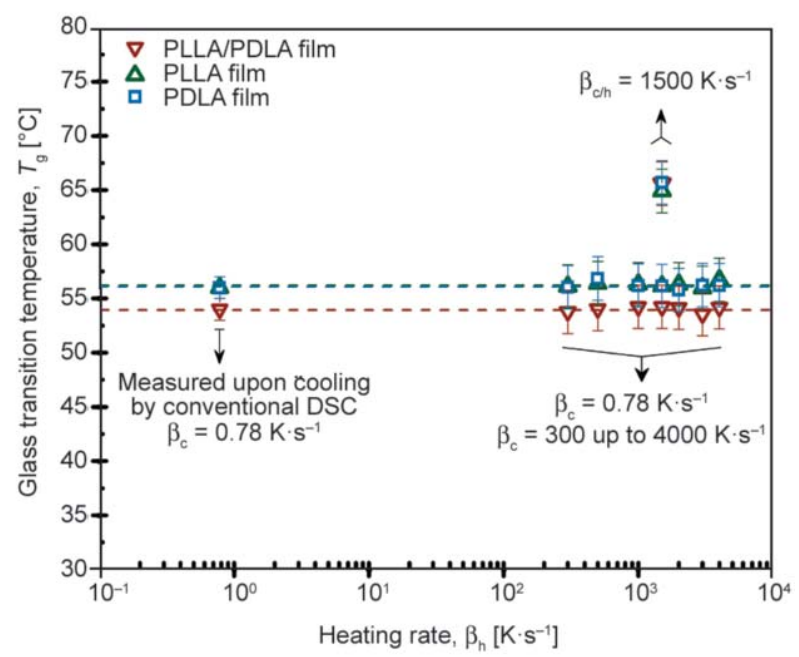

Figure 1. Glass transition temperatures of PLLA, PDLA and PLLA/PDLA films as a function of the heating rate $\beta_{\mathrm{h}}$ after cooling at $\left|\beta_{\mathrm{c}}\right|=0.78 \mathrm{~K} \cdot \mathrm{s}^{-1}$ or at $\beta_{\mathrm{c} / \mathrm{h}}=$ $1500 \mathrm{~K} \cdot \mathrm{s}^{-1}$. Dash line is an average of the values measured from FSC and DSC. 

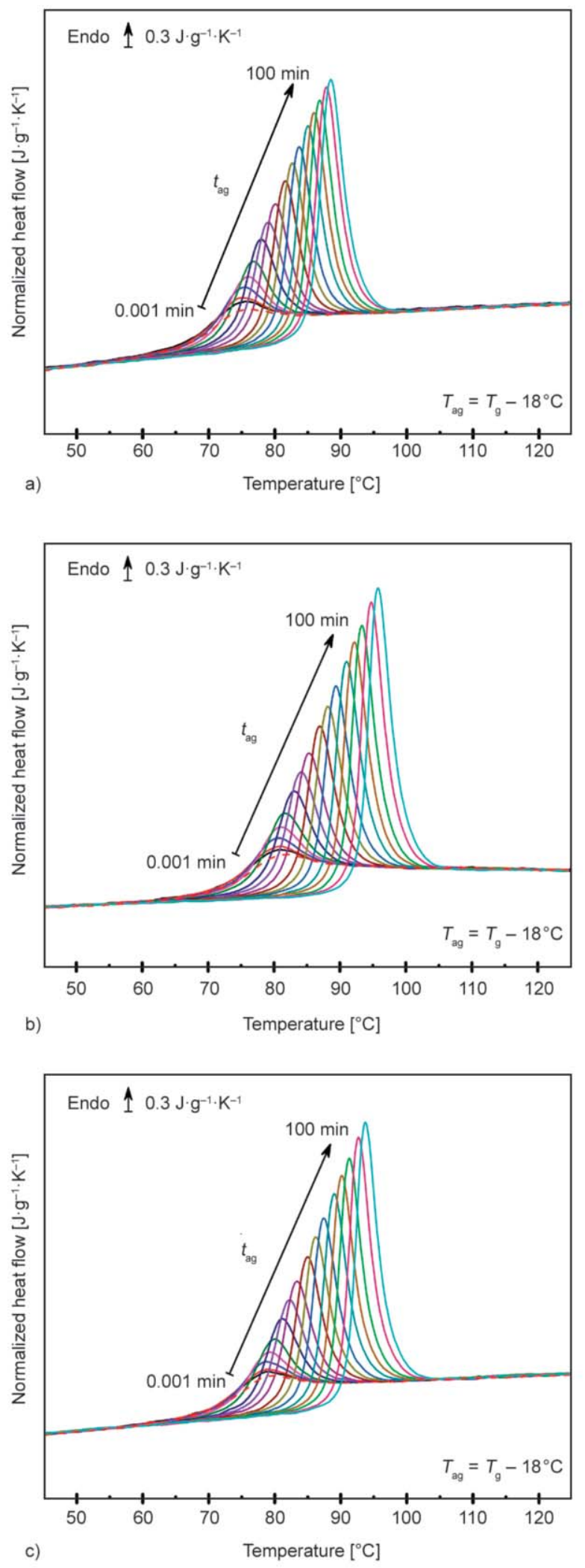

Figure 2. Curves of aged amorphous (a) PLLA, (b) PDLA and (c) PLLA/PDLA films obtained by FSC at aging temperature $T_{\mathrm{ag}}=T_{\mathrm{g}}-18^{\circ} \mathrm{C}$. FSC experiments were performed at the scanning rate of $\left|\beta_{\mathrm{c}}\right|=$ $\beta_{\mathrm{h}}=1500 \mathrm{~K} \cdot \mathrm{s}^{-1}$ for the aging times ranging from 0.001 up to $100 \mathrm{~min}$. Red dash lines correspond to the rejuvenated curves. that no significant difference of glass transition temperature could be noted between the three polymers, whatever the cooling rate.

Physical aging was carried out by FSC at the aging temperatures calculated according to the corrected $T_{\mathrm{g}}$ which are $66^{\circ} \mathrm{C}$ for PDLA, and $65^{\circ} \mathrm{C}$ for PLLA and PLLA/PDLA (after cooling at $\beta_{\mathrm{c}}=1500 \mathrm{~K} \cdot \mathrm{s}^{-1}$ ).

Figure 2 displays the normalized heat flows of aged samples from 0.001 up to $100 \mathrm{~min}$ at the temperature that is $18^{\circ} \mathrm{C}$ below the respective $T_{\mathrm{g}}$. Three other temperatures have been investigated and the variations of the normalized heat flow look similar. The same evolution of the endothermic relaxation peak is observed for all samples, namely the endothermic relaxation peak increases and shifts towards higher temperatures with the aging time increase, as usually reported for PLA-based systems [20, 34, 35]. The amount of enthalpy recovery of a glass aged at a temperature $T_{\mathrm{ag}}$ during an aging time $t_{\mathrm{ag}}$ is calculated by the integration of the difference between the thermograms of aged and rejuvenated samples in the temperature range, where the baselines of aged and rejuvenated samples coincide. It is assumed that the glass can reach the equilibrium in an infinite aging time. The estimated total enthalpy loss $\Delta H_{\infty}$ extrapolated from the equilibrium depends on the aging temperature $T_{\text {ag }}$ as well as on the glass transition temperature $T_{\mathrm{g}}$ and on the heat capacity step $\Delta C_{\mathrm{P}}$ of the samples as shown by Equation (4) [36]:

$$
\Delta H_{\infty}=\Delta C_{\mathrm{P}}\left(T_{\mathrm{g}}-T_{\mathrm{ag}}\right)
$$

The difference in the calculated total enthalpy loss $\Delta H_{\infty}$ is caused by the amplitude of the heat capacity step of samples, which is different for homopolymers and PLLA/PDLA, i.e. it is equal 0.46 and $0.54 \mathrm{~J} \cdot \mathrm{g}^{-1}$ for homopolymers and PLLA/PDLA, respectively. The aging rate can be determined as the slope of the linear fit and corresponds to the enthalpy change towards equilibrium. From Figure 3a, all studied samples have the similar rate of enthalpy recovery, which is $1.36 \pm 0.06 \mathrm{~J} \cdot \mathrm{decade}^{-1}$ as determined from the average of all samples. Figure $3 b$ presents the master curves of structural relaxation function versus the logarithm of the aging time for all the samples.

The master curves were plotted using a reference aging temperature of $T_{\mathrm{ag}}=T_{\mathrm{g}}-8^{\circ} \mathrm{C}$ and all other curves were shifted compared to the reference curve with the shift factor equal to $x=0.4$ for $T_{\text {ag }}=T_{\mathrm{g}}-5^{\circ} \mathrm{C}, x=-0.2$ for $T_{\text {ag }}=T_{\mathrm{g}}-13^{\circ} \mathrm{C}$ and 

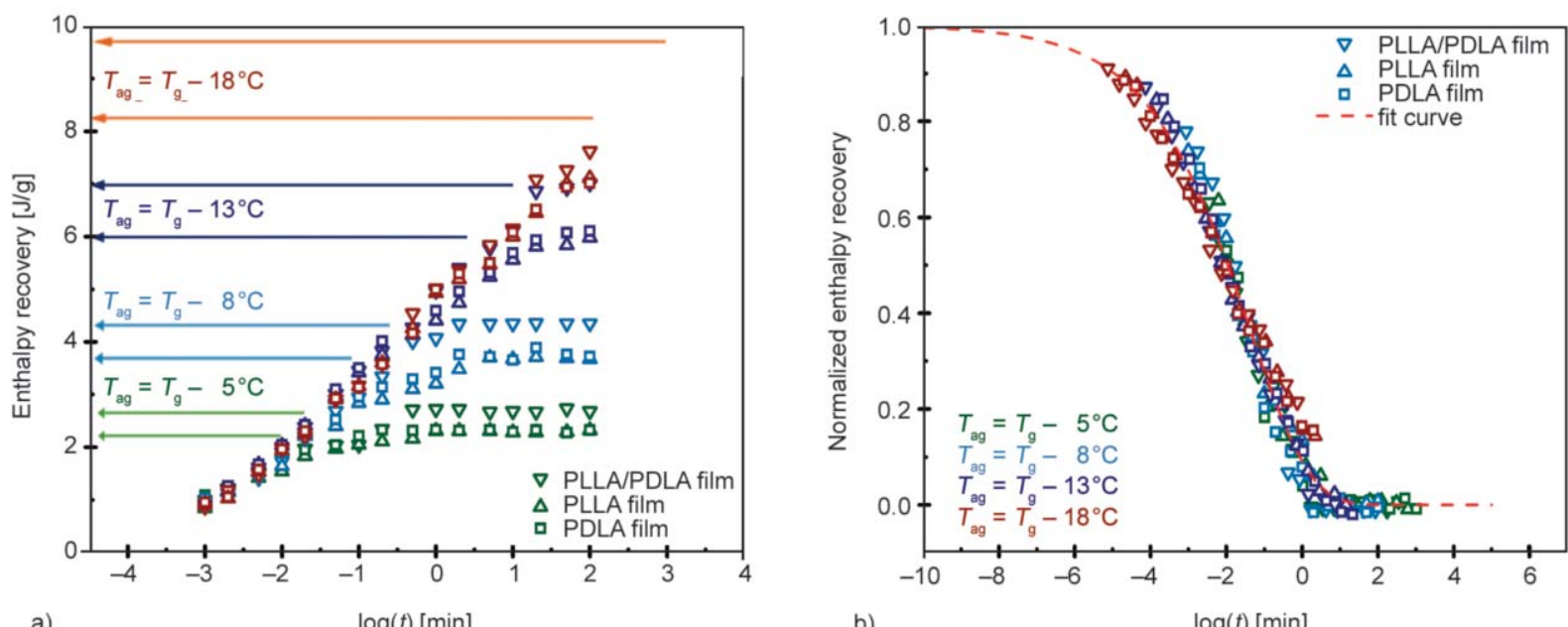

Figure 3. (a) Time evolution of the enthalpy recovery $\Delta H_{\mathrm{t}}$ for the aged amorphous PLLA (up triangle), PDLA (square) and PLLA/PDLA (down triangle) films at four aging temperatures: $T_{\mathrm{ag}}=T_{\mathrm{g}}-5^{\circ} \mathrm{C}$ (green symbols), $T_{\mathrm{ag}}=T_{\mathrm{g}}-8^{\circ} \mathrm{C}$ (light blue symbols), $T_{\mathrm{ag}}=T_{\mathrm{g}}-13^{\circ} \mathrm{C}$ (navy symbols), $T_{\mathrm{ag}}=T_{\mathrm{g}}-18^{\circ} \mathrm{C}$ (maroon symbols). The arrows show the values of calculated total enthalpy loss $\Delta H_{\infty}$ for homopolymers and PLLA/PDLA film. (b) Master curves plots of relaxation function $\left(\Phi(t)=\left(\Delta H_{\infty}-\delta H(t a)\right) / \Delta H_{\infty}\right)$. Reference aging temperature for shifting process is $T_{\mathrm{ag}}=T_{\mathrm{g}}-8^{\circ} \mathrm{C}$. Red dash line corresponds to the KWW fitting (Equation (5)).

$T_{\mathrm{ag}}=T_{\mathrm{g}}-18^{\circ} \mathrm{C}$. Interestingly it can be seen that the master curve of structural relaxation functions for all studied samples are superimposed and no discrimination between homopolymers and PLLA/PDLA glassy amorphous phases can be observed (Figure 3b). The master curve can be fitted by the KohlrauschWilliams-Watts (KWW) function [37] as shown by Equation (5):

$\Phi(t)=\mathrm{e}^{-\left(t / \tau_{\mathrm{KWw}}\right)^{\beta_{\mathrm{KWW}}}}$

where $\Phi(t)$ is the correlation function, $\beta_{\mathrm{KWw}}(0<$ $\left.\beta_{\mathrm{KWW}} \leq 1\right)$ is a stretch exponent, and $\tau_{\mathrm{KWW}}$ is the relaxation time. As shown in Figure 3, one KWW function is sufficient to fit all curves within the single relaxation time $\tau(0.041 \pm 0.002 \mathrm{~s})$ and the stretching exponent $\left(\beta_{\mathrm{KWW}}=0.274 \pm 0.005\right)$ according to the reference temperature. The kinetics of decays of the enthalpy recovery during the physical aging is exactly the same for all analyzed polymers. The glasses can completely relax their excess of energy in the range of studied aging time. Such results are on the contrary to the results of Ribelles and coworkers [38, 39], who considered that the thermodynamic equilibrium could not be reached due to the steric hindrances and the cooperativity of the molecular mobility induced during the structural relaxation. However, the obtained results match well with the recent work performed using FSC [28]. When the glasses are obtained by high cooling rates, accessible by means of FSC, the glass presents a high fictive temperature, a high level of enthalpy and, therefore, shorter relaxation time. Thus, thermodynamic equilibrium can be reached after few minutes to hours on the laboratory time scale. In addition, no influence of the tacticity on the structural relaxation is observed. This fact is in good agreement with the study of Androsch and Schick [40], who found that the relaxation of the glass towards the enthalpy of the supercooled liquid state is independent on the presence of the $D$-isomer co-units in the neat PLA chain. According to this observation, tacticity does not influence structural relaxation.

The isothermal dielectric spectra of PLLA/PDLA are shown as a function of frequency for different temperatures in Figure $4 \mathrm{a}$ and $4 \mathrm{~b}$ as examples of DRS analyses. All amorphous samples show two complex relaxation processes during relaxation investigations. The first one (Figure $4 a$ ) is the secondary relaxation $\beta$ observed at low frequencies and temperatures. This relaxation shifts towards higher frequency range as the temperature increases. The second relaxation (Figure $4 b$ ) is the primary relaxation $\alpha$ located in higher temperature region, and is well separated from the $\beta$ relaxation. Three Havriliak-Negami $(\mathrm{HN})$ complex functions (i.e. two for secondary complex relaxation function and one for the segmental relaxation) are used to fit isothermal dielectric loss spectra with a conductivity contribution to investigate the relaxation phenomena. The $\mathrm{HN}$ shape parameters for both $\beta$ and $\alpha$ relaxations in amorphous PLLA/PDLA were shown in Figure $4 c$ and $4 d$, respectively. All 

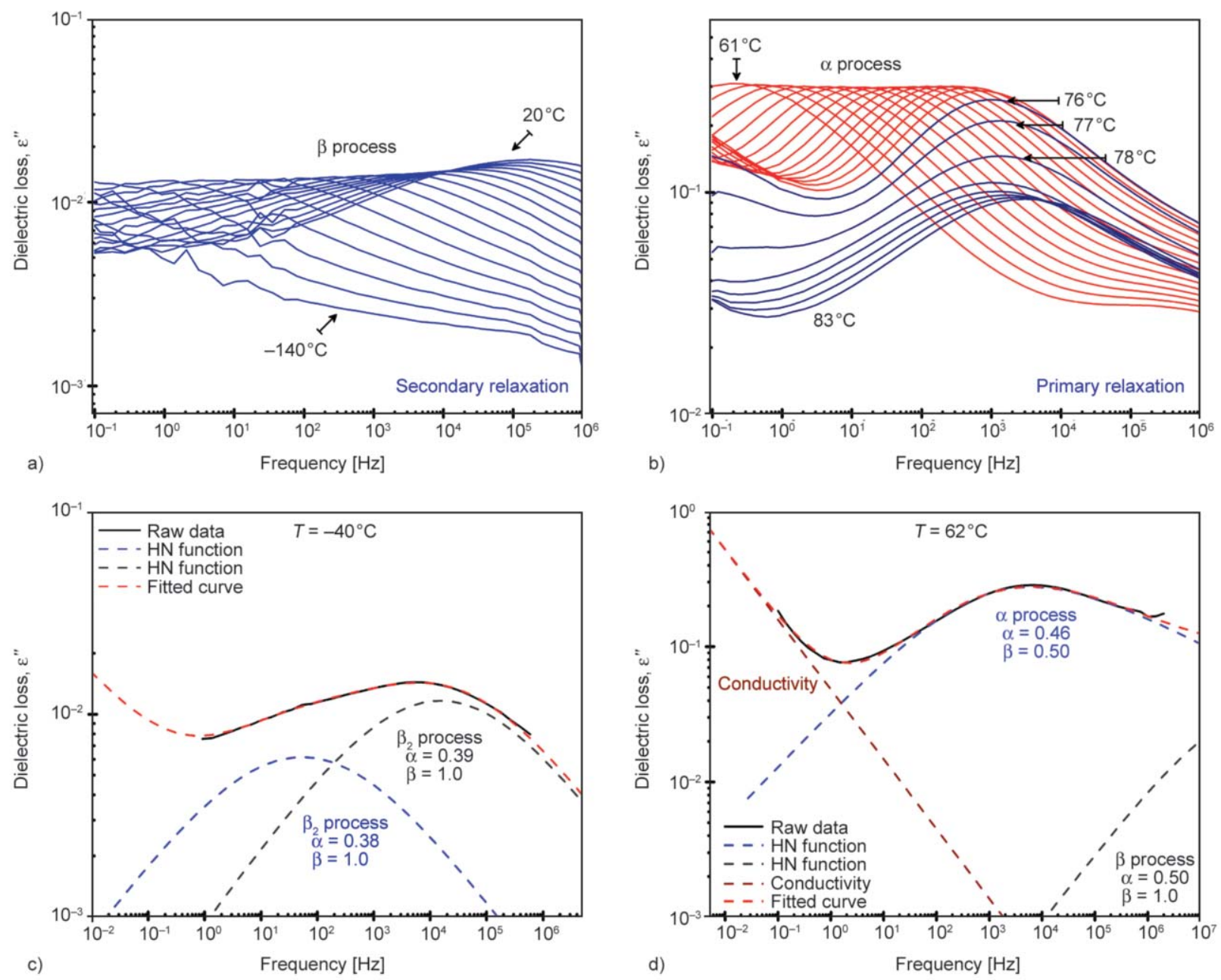

Figure 4. Imaginary parts of the complex dielectric permittivity $\varepsilon^{\prime \prime}$ vs frequency of amorphous PLLA/PDLA film (a) in the glassy state at temperature $T<T_{\mathrm{g}}$, (b) in the liquid state at temperature $T>T_{\mathrm{g}}$. Example of isothermal dielectric spectrum fitting (c) for secondary relaxation $\beta$ at $T=-40{ }^{\circ} \mathrm{C}$ and (d) primary $\alpha$ relaxation at $T=62{ }^{\circ} \mathrm{C}$ by $\mathrm{HN}$ complex functions.

amorphous samples have the same temperature dependence for the main relaxation processes, in which both $\alpha$ and $\beta$ relaxations shift to higher frequencies, but have the same amplitude as the temperature increases until the cold crystallization temperatures. As shown in Figure 4b, there is a strong reduction in the amplitude of dielectric loss above $T=75^{\circ} \mathrm{C}$ due to the cold crystallization during measurements. Therefore, the analytical procedure of fitting was carried out until the first crystallization appeared in order to ensure the thermo rheological simplicity of this process. The demonstration of complex secondary relaxation with two contributions agrees well with the results obtained for different polyesters, such as poly(ethylene terephthalate) (PET) [41, 42], PLA [43] and poly(hydroxyalkanoates) (PHAs) [44]. In addition, Soccio et al. [45] reported that such a broad $\beta$ relaxation phenomenon is caused by similar interactions between ester functional groups and the main polymer chain as well as stereocomplexation between enantiomers, PLLA and PDLA. In the case of poly(butylene 2,5-furanoate), the $\beta$ relaxation can be decomposed into two processes, one of them is a fast $\beta_{1}$ relaxation caused by the association of the mobile subunit with $\mathrm{C}-\mathrm{O}$ of the ester group, and the other one is a slow $\beta_{2}$ relaxation linked to the connection between the aromatic ring and $\mathrm{C}=\mathrm{O}$ of the ester group [46]. In the case of stereocomplexation, such a classical broad $\beta$ relaxation in polyesters may be caused by similar interactions of stereoselective van der Waals forces. Therefore, the isothermal spectra of $\beta$ relaxation were analyzed by two symmetrical $\mathrm{HN}$ functions, called Cole-Cole functions.

The dielectric relaxation strength $\Delta \varepsilon_{\alpha}$ of $\alpha$ relaxation is obtained by fitting the experimental data with the $\mathrm{HN}$ function (Equation (1)). In addition, as reported by Kremer and Schonhals [47], the values of $\Delta \varepsilon_{\alpha}$ depend on several parameters and can be also calculated 
by the generalized form of the Debye's theory as shown by Equation (6):

$$
\Delta \varepsilon_{\alpha}=\frac{1}{3 \varepsilon_{0}} g_{\mathrm{K}} \frac{\mu^{2}}{k_{\mathrm{B}} T} \frac{N}{V}
$$

where $\varepsilon_{0}$ is the dielectric permittivity of vacuum, $g_{\mathrm{K}}$ is the Kirkwood correlation factor which corresponds to the short-range intermolecular interactions leading to specific static dipole-dipole orientations, $\mu^{2}$ is the time-correlation function of the total dipole moment, $k_{\mathrm{B}}$ is the Boltzmann's constant, $T$ is the temperature, $N / V$ is the volume density of dipoles involved in the relaxation process. Figure 5 presents the isothermal dielectric spectra of all samples at $T=$ $341 \mathrm{~K}$ with the inset of the temperature dependence of $\Delta \varepsilon_{\alpha}$ in the $\alpha$ relaxation temperature range for PLLA, PDLA and PLLA/PDLA. In general, the dielectric relaxation strength $\Delta \varepsilon_{\alpha}$ decreases with temperature increasing [47-49]. Such a temperature dependence of $\Delta \varepsilon_{\alpha}$ was also reported for other kinds of glass-forming systems, i.e. polymers and thin polymer films [47, 48, 50]. As shown in Figure 5, the results indicate the same behavior of the dielectric strength $\Delta \varepsilon_{\alpha}$ for all studied samples. It means that the dielectric strength $\Delta \varepsilon_{\alpha}$ of PLLA/PDLA is similar to the dielectric strength of homopolymers in the range of uncertainty. The drastic reduction of the dielectric strength $\Delta \varepsilon_{\alpha}$ observed above $344 \mathrm{~K}$ for PDLA, $348 \mathrm{~K}$ for PLLA/PDLA, and $350 \mathrm{~K}$ for PLLA (see inset to Figure 5) is caused by the cold crystallization during the measurement.

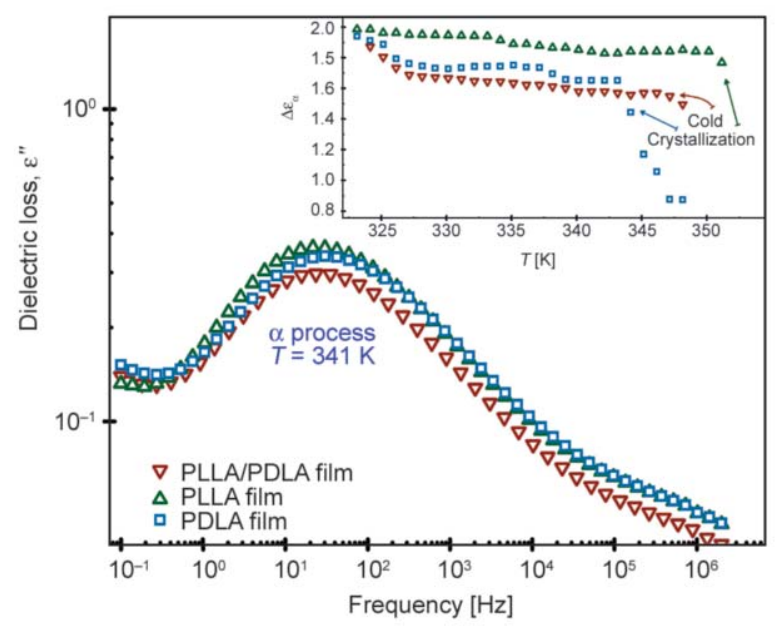

Figure 5. Dielectric loss $\varepsilon^{\prime \prime}$ of studied amorphous samples at $T=314 \mathrm{~K}$ as a function of frequency. Inset: the dielectric strength of $\alpha$ relaxation $\Delta \varepsilon_{\alpha}$ as a function of temperature in the range of $\alpha$ relaxation for amorphous PLLA, PDLA and PLLA/PDLA films.
The master plots of the dielectric loss for each isothermal spectrum are reported in Figure 6. The master curves were obtained by normalization of the spectra with the maximum of $\varepsilon^{\prime \prime}$ and its counterpart
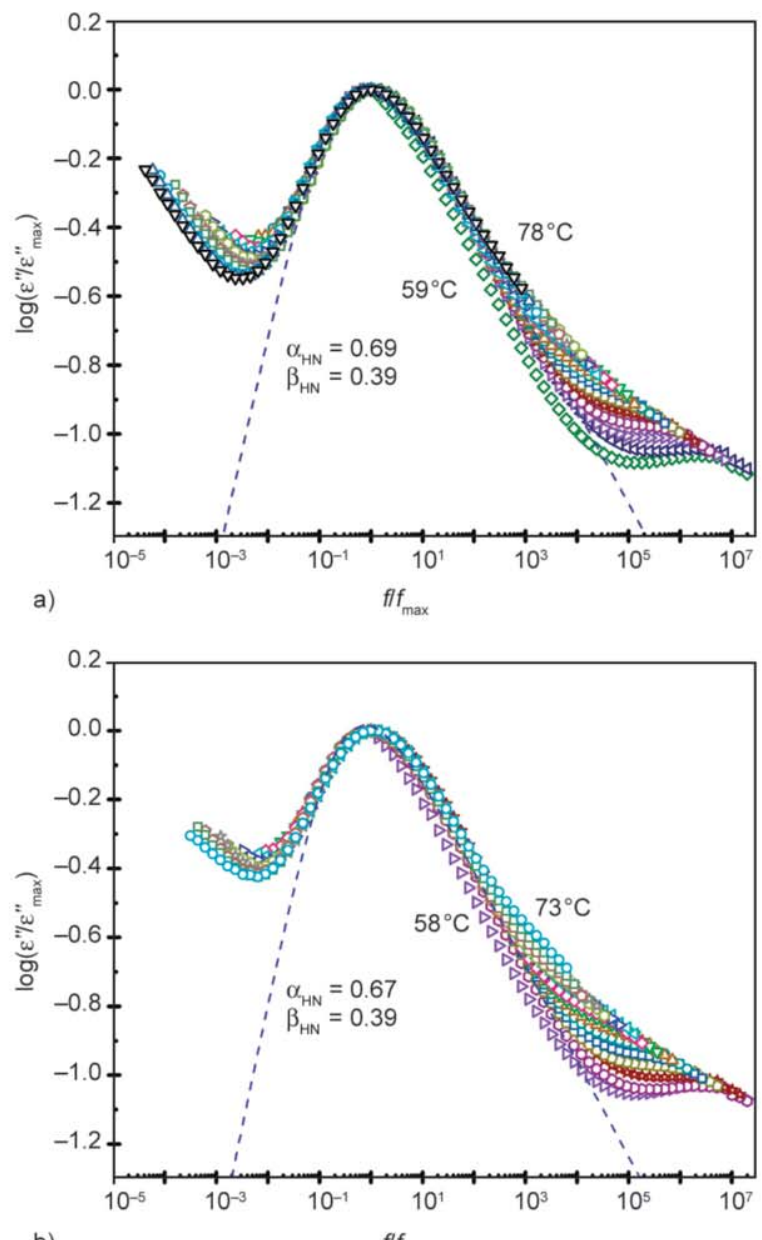

b)

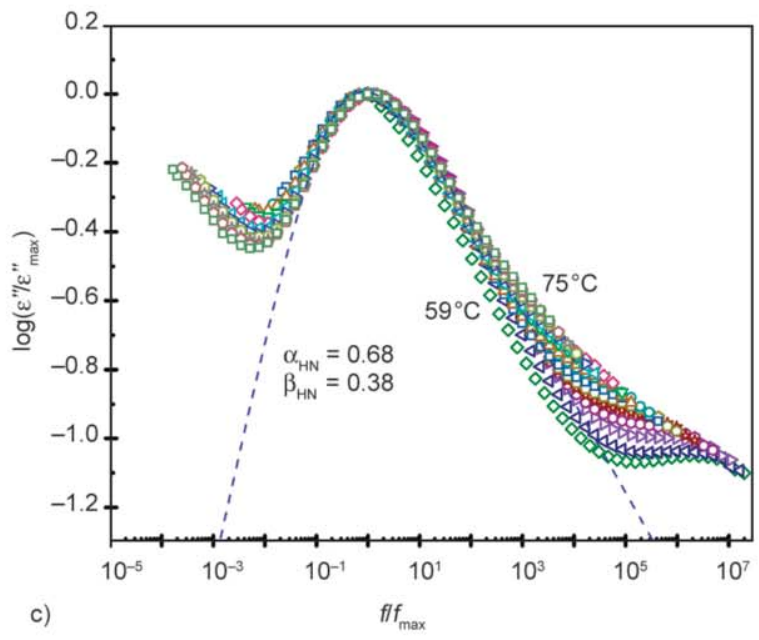

Figure 6. Log-log plot of the master curves of amorphous (a) PLLA, (b) PDLA and (c) PLLA/PDLA films. Light blue dash lines correspond to the HN fits (Equation (3). 
frequency at different temperatures (from 60 to $78^{\circ} \mathrm{C}$ with a step of $1{ }^{\circ} \mathrm{C}$ ). The results show very good overlap of all the curves forming a single master curve. On the other hand, systematic deviation from the master curve is observed in the high frequency range of the $\alpha$ relaxation. This kind of deviation can be explained by the contribution of noncooperative localized molecular mobility, such as $\beta$ relaxation. Such an interdependence of $\alpha$ and $\beta$ relaxations was reported also by Johari and Goldstein [51], and was investigated in glass-forming systems [52, 53]. While the temperature of measurement is increased, the impact of the $\beta$ relaxation increases on the master curves.

The determined experimentally values of $\alpha_{\mathrm{HN}}$ and $\beta_{\mathrm{HN}}$ are similar for the three materials and in agreement with the values reported in literature for PLAs [49, 54].

Taking into account the estimated values of $\tau_{\mathrm{HN}}, \alpha_{\mathrm{HN}}$ and $\beta_{\mathrm{HN}}$ parameters, the relaxation time $\tau_{\max }=$ $\left(2 \pi \cdot f_{\max }\right)^{-1}$ was also calculated according to Equation (7) [47]:

$\tau_{\max }=\tau_{\mathrm{HN}} \cdot\left[\frac{\sin \left(\frac{\alpha_{\mathrm{HN}} \beta_{\mathrm{HN}} \pi}{2+2 \beta_{\mathrm{HN}}}\right)}{\sin \left(\frac{\alpha_{\mathrm{HN}} \pi}{2+2 \beta_{\mathrm{HN}}}\right)}\right]^{1 / \alpha_{\mathrm{HN}}}$

The relaxation map presented in Figure 7 shows the evolution of the relaxation time $\tau_{\max }$ as a function of the inverse temperature for $\alpha$ and $\beta$ processes. For $\beta$ processes, the temperature dependence of the relaxation time is well described by the Arrhenius law given by Equation (8):

$\tau=\tau_{0, \mathrm{~A}} \exp \left(\frac{E_{a}}{R T}\right)$

where $E_{\mathrm{a}}$ is the activation energy of the $\beta$ relaxations, $R$ is the gas constant, and $\tau_{0, \mathrm{~A}}$ is a pre-exponential factor. The values of $E_{\mathrm{a}}$ of the $\beta_{1}$ relaxation are $64 \pm 10 \mathrm{~kJ} \cdot \mathrm{mol}^{-1}$ for PLLA, $57 \pm 12 \mathrm{~kJ} \cdot \mathrm{mol}^{-1}$ for PDLA and $65 \pm 10 \mathrm{~kJ} \cdot \mathrm{mol}^{-1}$ for PLLA/PDLA (Table 1). Such results are close to the results obtained for the other polyesters: $79 \pm 10 \mathrm{~kJ} \cdot \mathrm{mol}^{-1}$ for PET [55] and $36-46 \mathrm{~kJ} \cdot \mathrm{mol}^{-1}$ for PLA [43]. The values of activation energy of the $\beta_{2}$ relaxation are ranged from 21 to $24 \mathrm{~kJ} \cdot \mathrm{mol}^{-1}$ (Table 1). Such low values have been also observed for secondary relaxations associated with local molecular mobility of flexible units in aliphatic backbones [43]. In addition, the $E_{\mathrm{a}}$ value obtained for PLLA/PDLA is very close to the values obtained for PLLA and PDLA that can be explained

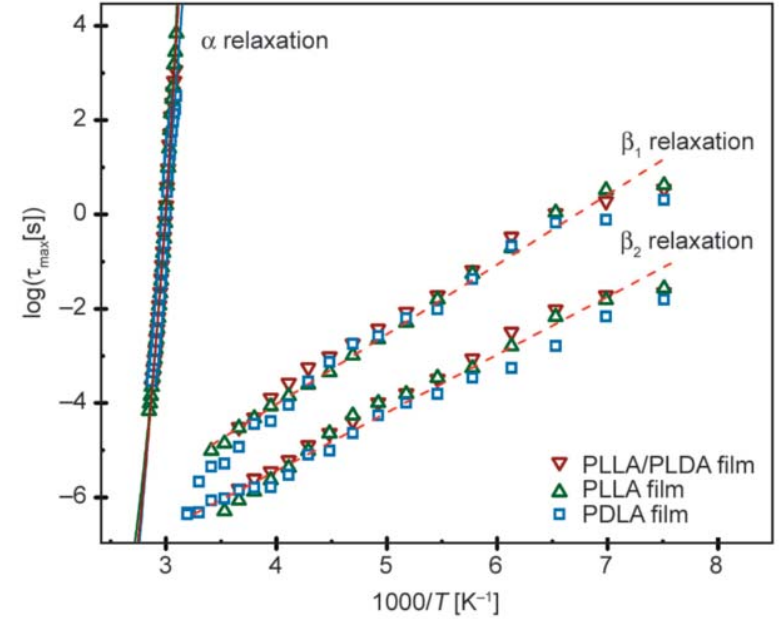

Figure 7. Structural $\alpha$ and $\beta$ relaxation times as a function of the inverse of temperature for amorphous PLLA, PDLA and PLLA/PDLA films.

by the similarity of the chemical structure of the repeating units of homopolymers and stereocomplex PLA. These results highlight the fact that chirality modifications in polylactide do not affect the global and local molecular mobility.

To investigate the molecular mobility in the segmental relaxation process, Angell's and Arrhenius plots were studied as shown in Figure 8. The temperature dependence of the relaxation time of the segmental relaxation can be fitted by a Vogel-Fulcher-Tamman (VFT) law, see Equation (9):

$\tau_{\max }=\tau_{0} \exp \left(\frac{D T_{0}}{T-T_{0}}\right)$

where $\tau_{\max }$ is the relaxation time at the maximum of the $\alpha$ relaxation, $D$ is the dimensionless parameter defined as the steepness strength, $T_{0}$ is a reference temperature, so called Vogel temperature, and $\tau_{0}$ is a pre-exponential factor. The Angell's plots for studied samples are practically all superimposed (Figure 8a). Furthermore, as one can see from Figure 8b, the temperature dependences of the relaxation frequency corresponding to the dielectric segmental relaxation peak $v_{\max }^{\alpha}$ for PLLA, PDLA and PLLA/PDLA are also superimposed. Such a behavior can be explained by the similar dynamic glass transition temperature (see in Table 1). The dielectric value of the glass transition temperature is usually selected as a temperature of a relaxation time equal to $100 \mathrm{~s}$. However, the temperatures obtained by DRS at the relaxation time equal to $10 \mathrm{~s}$ match much better with the dynamic glass transition temperatures obtained by MT-DSC with a period of $60 \mathrm{~s}$ [56]. Several studies of dielectric 
Table 1. Characteristic parameters obtained by DRS: the glass transition temperature at $\tau=100$ and $10 \mathrm{~s}$.

\begin{tabular}{|c|c|c|c|c|c|c|c|c|c|}
\hline \multirow[t]{2}{*}{ Samples } & \multirow{2}{*}{$\begin{array}{c}T_{\mathrm{g}, \tau}=100 \mathrm{~s} \\
{\left[{ }^{\circ} \mathrm{C}\right]}\end{array}$} & \multirow{2}{*}{$\begin{array}{c}T_{\mathrm{g}, \tau}=10 \mathrm{~s} \\
{\left[{ }^{\circ} \mathrm{C}\right]}\end{array}$} & \multirow{2}{*}{$\begin{array}{c}\boldsymbol{T}_{\mathrm{g}}{ }^{*} \\
{\left[{ }^{\circ} \mathbf{C}\right]}\end{array}$} & \multirow[t]{2}{*}{$D$} & \multirow{2}{*}{$\begin{array}{c}T_{0} \\
{\left[{ }^{\circ} \mathrm{C}\right]}\end{array}$} & \multirow{2}{*}{$\begin{array}{c}\log \left(\tau_{0}\right) \\
{[\mathbf{s}]}\end{array}$} & \multirow[t]{2}{*}{$m$} & \multicolumn{2}{|c|}{$\begin{array}{c}E_{\mathrm{a}} \\
{\left[\mathrm{kJ} \cdot \mathrm{mol}^{-1}\right]}\end{array}$} \\
\hline & & & & & & & & $\beta_{1}$ & $\beta_{2}$ \\
\hline PLLA & 55.3 & 58.2 & 59.3 & 3.5 & 22.4 & -13 & 146 & 64 & 24 \\
\hline PDLA & 54.6 & 57.0 & 58.4 & 5.7 & 25.6 & -15 & 146 & 57 & 21 \\
\hline PLLA/PDLA & 55.7 & 58.6 & 59.1 & 4.3 & 25.8 & -14 & 150 & 65 & 23 \\
\hline PLA [59] & 54 & 54 & & 5 & 17 & -14 & 141 & & \\
\hline
\end{tabular}

$D$ is dimensionless parameter of the VFT equation (Equation (9)); $T_{0}$ is reference temperature; $\tau_{0}$ is the relaxation time extrapolated to an infinite temperature; $m$ is the fragility index; $E_{\mathrm{a}}$ is the activation energy of the $\beta_{1}$ relaxation. $T_{\mathrm{g}}{ }^{*}$ is the glass transition temperature obtained by MT-DSC analysis.

values of the glass transition temperature may be found in literature that reveal good agreement with the values observed by thermal techniques, such as DSC and MT-DSC [57, 58]. The degree of deviation from Arrhenius-type temperature dependence near $T_{\mathrm{g}}$ allows a classification of glass-formers on the basis of the structural relaxation, so called 'fragility concept' $[59,60]$ as shown by Equation (10):

$m=\left.\frac{\mathrm{d} \log \left(\tau_{\max }\right)}{\mathrm{d}\left(\frac{T_{g}}{T}\right)}\right|_{T=T_{\mathrm{g}}}$

where $T_{\mathrm{g}} / T$ is the temperature normalized with respect to the glass transition temperature $T_{\mathrm{g}, \tau=100 \mathrm{~s}}$. All calculated parameters are gathered in Table 1 .

The values of fragility index $m$ obtained for homopolymers and PLLA/PDLA are found to be 146 and 150, respectively. Therefore, PLLA/PDLA has similar fragility index and glass transition temperature as neat PLA and homopolymers (Table 1). This

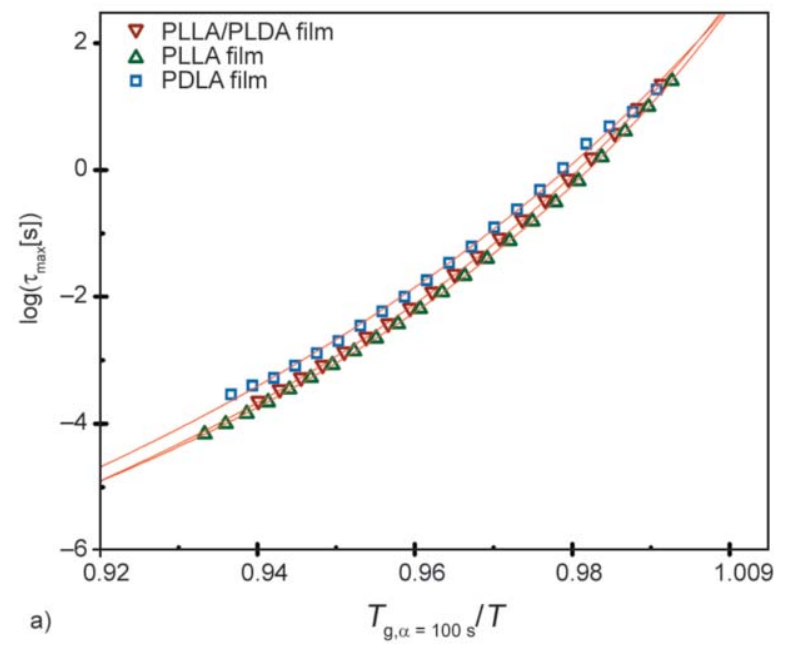

result means that these polymers correspond to 'fragile' glass-formers. Such fragility results can be correlated to the molecular structure with extended van der Waals interactions and/or hydrogen bonds between polymers chains [59,61]. Many researches proposed the relationship between the cooperativity, the glass transition temperature and the fragility index of polymers [62]. Previously, Chua et al. [63] combined DRS, MT-DSC and Ac-chip calorimetry in order to study the molecular mobility of poly(styrene) (PS) and poly(methyl methacrylate) (PMMA) samples. The authors found that the different experimental techniques allowed obtaining consistent results of cooperativity length correlated with the structural relaxation temperature and time dependence. Therefore, the combination of MT-DSC and DRS enables us to calculate the temperature dependence of the cooperativity number of relaxing entities $N_{\alpha}$ in a wide temperature range [64] according to Donth's approach (see ref [65] for calculation).

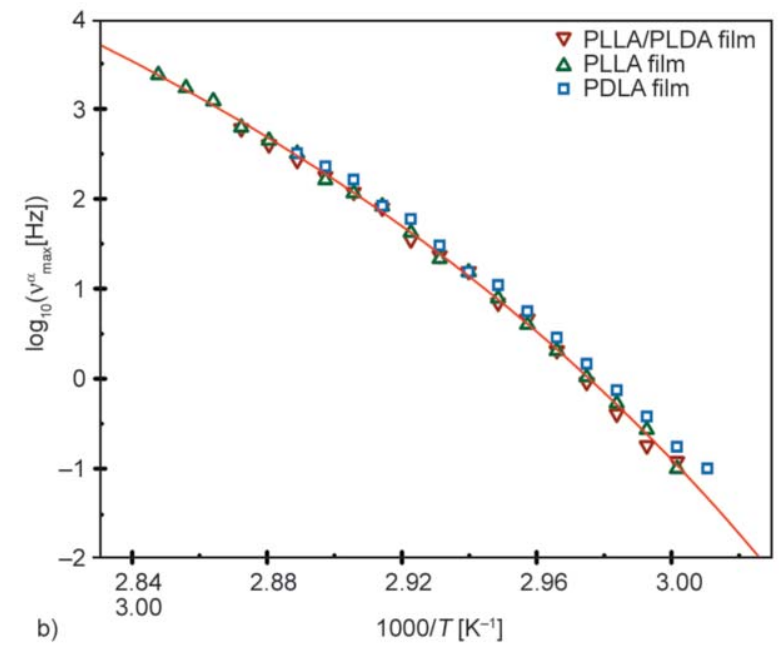

Figure 8. (a) Relaxation time $\tau_{\max }$ as a function of normalized temperature $T_{\mathrm{g}, \tau=100 \mathrm{~s}} / T$ (the Angell's plot), (b) Arrhenius plot of the $\alpha$ relaxation process for the amorphous PLLA, PDLA and PLLA/PDLA films. The symbols correspond to the experimental data and the red lines represent the VFT fits. $T_{\mathrm{g}}$ corresponds to $\tau=100 \mathrm{~s}$ and $v_{\max }^{\alpha}$ is a relaxation rate equivalent to $1 / \tau_{\max }$, where $\tau_{\max }=1 /\left(2 \pi f_{\max }\right)$. 
The cooperativity number $N_{\alpha}$ and the corresponding cooperativity length $\xi_{\alpha}$ as a function of normalized temperature for all investigated samples are shown in Figure 9a and Figure 9b, respectively. As one can see, the cooperativity length $\xi_{\alpha}$ is dependent on the relaxation time and the glass transition temperature. A nonlinear increase of the cooperativity length $\xi_{\alpha}$ and the cooperativity number $N_{\alpha}$ with decreasing temperature and increasing relaxation time is observed for each sample. All studied samples have similar behavior regarding temperature dependence of the cooperativity parameters. The similarity in the cooperativity length of homopolymers and stereocomplex PLA could also be correlated with the results of the fragility index $m$ of samples [66,67].

It should be noted that the extrapolation of the cooperativity length $\xi_{\alpha}$ estimated from DRS over a wide range of relaxation temperature fits very well with the values determined by MT-DSC (star shape symbols in Figure 9), $T_{\alpha}$ at $\tau \approx 10 \mathrm{~s}$ as well as with the cooperativity number $N_{\alpha}$. However, such a non-linear temperature dependence of $\xi_{\alpha}$ and $N_{\alpha}$ can be related to the temperature dependence of the relaxation time. The cooperativity length $\xi_{\alpha}$ at $T_{\alpha}$ for all the samples are quite similar, i.e. $2.9 \pm 0.2 \mathrm{~nm}$ for PLLA and PLLA/PDLA, and $2.8 \pm 0.2 \mathrm{~nm}$ for PDLA, independently from stereocomplexation. Furthermore, the obtained values are rather close to the results obtained by Rijal et al. [67] for a commercial PLA (Figure 9). It is interesting to compare the results of this work with the results of Hamonic et al. [68] obtained for PET with different microstructure, i.e. wholly amorphous and isotropic PET and semi-crystalline PET

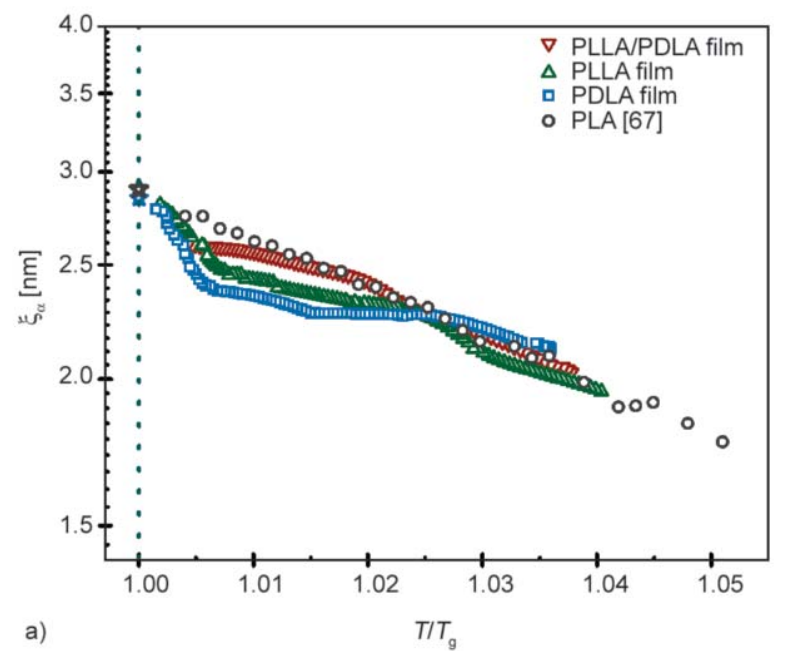

drawn at two different draw ratio $\lambda$. The authors showed an important influence of the microstructure on the temperature dependence of the cooperativity. If the amorphous phase is anisotropic and constrained by crystallites (i.e. highly drawn PET, $\lambda=6.0$ ), the CRR size and $N_{\alpha}$ are very small. These results revealed that cooperativity could vary a lot in the amorphous part of the polymer, but in the case of PLA, stereocomplexation has no significant influence.

\section{Conclusions}

Amorphous phase of stereocomplex PLA is investigated and compared to that of homopolymers (PLLA and PDLA). The influence of the tacticity on the glassy dynamics of poly(lactides) was studied in terms of physical aging and segmental ( $\alpha$ process) relaxation by FSC and DRS, respectively. Fictive temperatures and different determination of the glass transition (by FSC, MT-DSC or DRS) allow obtaining the same values for PLLA, PDLA and stereocomplex PLA. The kinetics of enthalpy recovery for amorphous stereocomplex PLA and homopolymers (PLLA and PDLA) were investigated by FSC measurements. The results reveal that the enthalpy recovery has a single step decay towards equilibrium and glasses are allowed to completely relax in the range of aging time. It is found that the relaxation kinetics of the glass towards the enthalpy recovery of the supercooled liquid is independent on the tacticity in the stereocomplex structure.

Furthermore, the $\alpha$ and $\beta$ processes of wholly amorphous samples were examined to study the dielectric properties, such as relaxation time, dielectric strength,

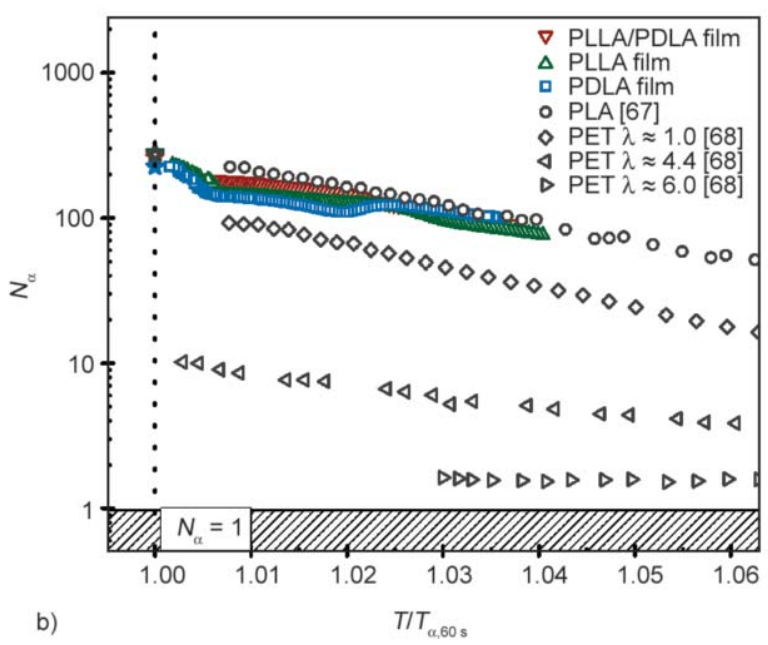

Figure 9. (a) The cooperativity length $\xi_{\alpha}$ versus normalized temperature obtained from DRS measurements at period $=60 \mathrm{~s}$, $\tau \sim 10 \mathrm{~s}$. (b) $N_{\alpha}$ as a function of normalized temperature. The star shaped symbols at $T / T_{\mathrm{g}}=1$ and $T / T_{\alpha, 60 \mathrm{~s}}=1$ correspond to the results determined from MT-DSC analyses at $T_{\alpha}$ at $\tau \approx 10 \mathrm{~s}$. 
and fragility. It is found that all samples have the similar dielectric properties independently on the sample tacticity. The values of cooperativity length $\xi_{\alpha}$ estimated from Donth's approach for PLLA, PDLA and stereocomplex PLA are found to be similar at the glass transition $(\approx 2.9 \mathrm{~nm})$ and in a wide temperature range.

Therefore, one can conclude that the cooperativity length $\xi_{\alpha}$ does not depend on the polymer chirality. As observed through vitrification kinetics investigations, no effect of stereocomplexation is observed on the dynamics. Finally, it could be concluded that the kinetics of the segmental relaxation of wholly amorphous stereocomplex PLA and the amorphous phases of PLAs are the same, even if crystallization leads to different crystalline phase for homopolymers and stereocomplex PLA. This study highlights the fact that the chirality has no effect on the molecular mobility relaxation processes in the amorphous state. This result was also observed for other kinds of glass forming molecules. Taking the obtained results into account one may conclude that the molecular mobility investigated by FSC and DRS is not the main factor influencing the crystallization phenomenon. So, it can be hypothesized that the specific interaction at the origin of the appearance of the stereocomplex crystals could be investigated by others techniques in higher temperature range or in another length scale.

\section{Acknowledgements}

The authors are grateful to the European Union and the Normandy Region for the financial support given to the MACHI project via the 'Fonds Européen de Développement Régionale’ (FEDER).

\section{References}

[1] Slager J., Domb A. J.: Biopolymer stereocomplexes. Advanced Drug Delivery Reviews, 55, 549-583 (2003). https://doi.org/10.1016/S0169-409X(03)00042-5

[2] Pauling L., Corey R. B.: Two rippled-sheet configurations of polypeptide chains, and a note about the pleated sheets. Proceedings of the National Academy of Sciences of the United States of America, 39, 253-256 (1953). https://doi.org/10.1073/pnas.39.4.253

[3] Fox T. G., Garrett B. S., Goode W. E., Gratch S., Kincaid J. F., Spell A., Stroupe J. D.: Crystalline polymers of methyl methacrylate. Journal of the American Chemical Society, 80, 1768-1769 (1958).

https://doi.org/10.1021/ja01540a068
[4] Nampoothiri K. M., Nair N. R., John R. P.: An overview of the recent developments in polylactide (PLA) research. Bioresource Technology, 101, 8493-8501 (2010). https://doi.org/10.1016/j.biortech.2010.05.092

[5] Vert M., Li S. M., Spenlehauer G., Guerin P.: Bioresorbability and biocompatibility of aliphatic polyesters. Journal of Materials Science: Materials in Medicine, 3, 432-446 (1992). https://doi.org/10.1007/BF00701240

[6] Tsuji H., Ikada Y.: Properties and morphologies of poly(L-lactide): 1. Annealing condition effects on properties and morphologies of poly(L-lactide). Polymer, 36, 2709-2716 (1995).

https://doi.org/10.1016/0032-3861(95)93647-5

[7] Hortós M., Viñas M., Espino S., Bou J. J.: Influence of temperature on high molecular weight poly(lactic acid) stereocomplex formation. Express Polymer Letters, 13, 123-134 (2019).

https://doi.org/10.3144/expresspolymlett.2019.12

[8] Okihara T., Tsuji M., Kawaguchi A., Katayama K-I., Tsuji H., Hyon S-H., Ikada Y.: Crystal structure of stereocomplex of poly(L-lactide) and poly(D-lactide). Journal of Macromolecular Science Part B: Physics, 30, 119-140 (1991).

https://doi.org/10.1080/00222349108245788

[9] Tsuji H., Hyon S. H., Ikada Y.: Stereocomplex formation between enantiomeric poly(lactic acid)s. 3. Calorimetric studies on blend films cast from dilute solution. Macromolecules, 24, 5651-5656 (1991).

https://doi.org/10.1021/ma00020a026

[10] Tsuji H., Ikada Y.: Stereocomplex formation between enantiomeric poly(lactic acid)s. XI. Mechanical properties and morphology of solution-cast films. Polymer, 40, 6699-6708 (1999). https://doi.org/10.1016/S0032-3861(99)00004-X

[11] Tsuji H., Tezuka Y.: Stereocomplex formation between enantiomeric poly(lactic acid)s. 12. Spherulite growth of low-molecular-weight poly(lactic acid)s from the melt. Biomacromolecules, 5, 1181-1186 (2004). https://doi.org/10.1021/bm049835i

[12] Tsuji H., Ikada Y.: Stereocomplex formation between enantiomeric poly(lactic acids). 9. Stereocomplexation from the melt. Macromolecules, 26, 6918-6926 (1993). https://doi.org/10.1021/ma00077a032

[13] Tashiro K., Kouno N., Wang H., Tsuji H.: Crystal structure of poly(lactic acid) stereocomplex: Random packing model of PDLA and PLLA chains as studied by X-ray diffraction analysis. Macromolecules, 50, 80488065 (2017). https://doi.org/10.1021/acs.macromol.7b01468

[14] Woo E. M., Chang L.: Crystallization and morphology of stereocomplexes in nonequimolar mixtures of poly (L-lactic acid) with excess poly(D-lactic acid). Polymer, 52, 6080-6089 (2011). https://doi.org/10.1016/j.polymer.2011.11.002 
[15] Soto Puente J. A., Fatyeyeva K., Chappey C., Marais S., Dargent E.: Layered poly(ethylene-co-vinyl acetate)/ poly(ethylene-co-vinyl alcohol) membranes with enhanced water separation selectivity and performance. American Chemical Society Applied Materials and Interfaces, 9, 6411-6423 (2017).

https://doi.org/10.1021/acsami.6b14909

[16] Badrinarayanan P., Zheng W., Li Q., Simon S. L.: The glass transition temperature versus the fictive temperature. Journal of Non-Crystalline Solids, 353, 2603-2612 (2007). https://doi.org/10.1016/j.jnoncrysol.2007.04.025

[17] Moynihan C. T., Easteal A. J., De Bolt M. A., Tucker J.: Dependence of the fictive temperature of glass on cooling rate. Journal of the American Ceramic Society, 59, 12-16 (1976). https://doi.org/10.1111/j.1151-2916.1976.tb09376.x

[18] Debenedetti P. G., Truskett T. M., Lewis C. P., Stillinger F. H.: Theory of supercooled liquids and glasses: Energy landscape and statistical geometry perspectives. Advances in Chemical Engineering, Academic Press, 28, 21-79 (2001).

https://doi.org/10.1016/S0065-2377(01)28003-X

[19] Struik L. C. E.: Physical aging in plastics and other glassy materials. Polymer Engineering and Science, 17, 165-173 (1977). https://doi.org/10.1002/pen.760170305

[20] Dobircau L., Delpouve N., Herbinet R., Domenek S., le Pluart L., Laurent D., Ducruet V., Dargent E.: Molecular mobility and physical ageing of plasticized poly (lactide). Polymer Engineering and Science, 55, 858865 (2015).

https://doi.org/10.1002/pen.23952

[21] Adam G., Gibbs J. H.: On the temperature dependence of cooperative relaxation properties in glass-forming liquids. The Journal of Chemical Physics, 43, 139-146 (1965).

https://doi.org/10.1063/1.1696442

[22] Wang Y., Funari S. S., Mano J.: Influence of semicrystalline morphology on the glass transition of poly $(\mathrm{L}-$ lactic acid). Macromolecular Chemistry and Physics, 207, 1262-1271 (2006).

https://doi.org/10.1002/macp.200600114

[23] Monnier X., Nassar S. F., Domenek S., Guinault A., Sollogoub C., Dargent E., Delpouve N.: Reduced physical aging rates of polylactide in polystyrene/polylactide multilayer films from fast scanning calorimetry. Polymer, 150, 1-9 (2018).

https://doi.org/10.1016/j.polymer.2018.07.017

[24] Nassar S. F., Domenek S., Guinault A., Stoclet G., Delpouve N., Sollogoub C.: Structural and dynamic heterogeneity in the amorphous phase of poly(L,L-lactide) confined at the nanoscale by the coextrusion process. Macromolecules, 51, 128-136 (2018). https://doi.org/10.1021/acs.macromol.7b02188
[25] Monnier X., Delpouve N., Basson N., Guinault A., Domenek S., Saiter A., Mallon P. E., Dargent E.: Molecular dynamics in electrospun amorphous plasticized polylactide fibers. Polymer, 73, 68-78 (2015). https://doi.org/10.1016/j.polymer.2015.07.047

[26] Saiter A., Delpouve N., Dargent E., Oberhauser W., Conzatti L., Cicogna F., Passaglia E.: Probing the chain segment mobility at the interface of semi-crystalline polylactide/clay nanocomposites. European Polymer Journal, 78, 274-289 (2016).

https://doi.org/10.1016/j.eurpolymj.2016.03.040

[27] Araujo S., Delpouve N., Dhotel A., Domenek S., Guinault A., Delbreilh L., Dargent E.: Reducing the gap between the activation energy measured in the liquid and the glassy states by adding a plasticizer to polylactide. American Chemical Society Omega, 3, 17092-17099 (2018).

https://doi.org/10.1021/acsomega.8b02474

[28] Monnier X., Saiter A., Dargent E.: Physical aging in PLA through standard DSC and fast scanning calorimetry investigations. Thermochimica Acta, 648, 13-22 (2017). https://doi.org/10.1016/j.tca.2016.12.006

[29] Mathot V., Pyda M., Pijpers T., Vanden Poel G., van de Kerkhof E., van Herwaarden S., van Herwaarden F., Leenaers A.: The flash DSC 1, A power compensation twin-type, chip-based fast scanning calorimeter (FSC): First findings on polymers. Thermochimica Acta, 522, 36-45 (2011).

https://doi.org/10.1016/j.tca.2011.02.031

[30] Schawe J. E. K.: Measurement of the thermal glass transition of polystyrene in a cooling rate range of more than six decades. Thermochimica Acta, 603, 128-134 (2015).

https://doi.org/10.1016/j.tca.2014.05.025

[31] Havriliak S., Negami S.: A complex plane representation of dielectric and mechanical relaxation processes in some polymers. Polymer, 8, 161-210 (1967). https://doi.org/10.1016/0032-3861(67)90021-3

[32] Gao S., Simon S. L.: Measurement of the limiting fictive temperature over five decades of cooling and heating rates. Thermochimica Acta, 603, 123-127 (2015). https://doi.org/10.1016/j.tca.2014.08.019

[33] Dhotel A., Rijal B., Delbreilh L., Dargent E., Saiter A.: Combining flash DSC, DSC and broadband dielectric spectroscopy to determine fragility. Journal of Thermal Analysis and Calorimetry, 121, 453-461 (2015). https://doi.org/10.1007/s10973-015-4650-9

[34] Pan P., Zhu B., Inoue Y.: Enthalpy relaxation and embrittlement of poly(L-lactide) during physical aging. Macromolecules, 40, 9664-9671 (2007). https://doi.org/10.1021/ma071737c

[35] Celli A., Scandola M.: Thermal properties and physical ageing of poly (L-lactic acid). Polymer, 33, 2699-2703 (1992). https://doi.org/10.1016/0032-3861(92)90440-8 
[36] Hodge I. M.: Enthalpy relaxation and recovery in amorphous materials. Journal of Non-Crystalline Solids, 169, 211-266 (1994).

https://doi.org/10.1016/0022-3093(94)90321-2

[37] Williams G., Watts D. C.: Non-symmetrical dielectric relaxation behaviour arising from a simple empirical decay function. Transactions of the Faraday Society, 66, 80-85 (1970).

https://doi.org/10.1039/tf9706600080

[38] Salmerón Sánchez M., Touzé Y., Saiter A., Saiter J. M., Gómez Ribelles J. L.: Influence of the chemical structure on the kinetics of the structural relaxation process of acrylate and methacrylate polymer networks. Colloid and Polymer Science, 283, 711-720 (2005).

https://doi.org/10.1007/s00396-004-1207-z

[39] Ribelles J. L. G., Pradas M. M.: Structural relaxation of glass-forming polymers based on an equation for configurational entropy. 1. DSC experiments on polycarbonate. Macromolecules, 28, 5867-5877 (1995).

https://doi.org/10.1021/ma00121a025

[40] Androsch R., Schick C.: Interplay between the relaxation of the glass of random L/D-lactide copolymers and homogeneous crystal nucleation: Evidence for segregation of chain defects. The Journal of Physical Chemistry B, 120, 4522-4528 (2016).

https://doi.org/10.1021/acs.jpcb.6b03022

[41] Sperling L. H.: Introduction to physical polymer science. Wiley, Hoboken (2005).

https://doi.org/10.1002/0471757128

[42] Okazaki I., Wunderlich B.: Reversible local melting in polymer crystals. Macromolecular Rapid Communications, 18, 313-318 (1997).

https://doi.org/10.1002/marc.1997.030180407

[43] Starkweather H. W., Avakian P., Fontanella J. J., Wintersgill M. C.: Internal motions in polylactide and related polymers. Macromolecules, 26, 5084-5087 (1993). https://doi.org/10.1021/ma00071a016

[44] Crétois R., Delbreilh L., Dargent E., Follain N., Lebrun L., Saiter J. M.: Dielectric relaxations in polyhydroxyalkanoates/organoclay nanocomposites. European Polymer Journal, 49, 3434-3444 (2013).

https://doi.org/10.1016/j.eurpolymj.2013.07.009

[45] Soccio M., Martínez-Tong D. E., Alegría A., Munari A., Lotti N.: Molecular dynamics of fully biobased poly (butylene 2,5-furanoate) as revealed by broadband dielectric spectroscopy. Polymer, 128, 24-30 (2017). https://doi.org/10.1016/j.polymer.2017.09.007

[46] Bourdet A., Esposito A., Thiyagarajan S., Delbreilh L., Affouard F., Knoop R. J. I., Dargent E.: Molecular mobility in amorphous biobased poly(ethylene 2,5-furandicarboxylate) and poly(ethylene 2,4-furandicarboxylate). Macromolecules, 51, 1937-1945 (2018).

https://doi.org/10.1021/acs.macromol.8b00108

[47] Kremer F., Schönhals A.: Broadband dielectric spectroscopy. Springer, New York (2003).

https://doi.org/10.1007/978-3-642-56120-7
[48] Yin H., Napolitano S., Schönhals A.: Molecular mobility and glass transition of thin films of poly(bisphenol A carbonate). Macromolecules, 45, 1652-1662 (2012). https://doi.org/10.1021/ma202127p

[49] Mano J. F., Gómez Ribelles J. L., Alves N. M., Salmerón Sanchez M.: Glass transition dynamics and structural relaxation of PLLA studied by DSC: Influence of crystallinity. Polymer, 46, 8258-8265 (2005).

https://doi.org/10.1016/j.polymer.2005.06.096

[50] Rotella C., Napolitano S., De Cremer L., Koeckelberghs G., Wübbenhorst M.: Distribution of segmental mobility in ultrathin polymer films. Macromolecules, 43, 8686-8691 (2010).

https://doi.org/10.1021/ma101695y

[51] Johari G. P., Goldstein M.: Viscous liquids and the glass transition. II. secondary relaxations in glasses of rigid molecules. The Journal of Chemical Physics, 53, 23722388 (1970).

https://doi.org/10.1063/1.1674335

[52] Kessairi K., Capaccioli S., Prevosto D., Lucchesi M., Sharifi S., Rolla P. A.: Interdependence of primary and Johari-Goldstein secondary relaxations in glass-forming systems. The Journal of Physical Chemistry B, 112, 4470-4473 (2008).

https://doi.org/10.1021/jp800764w

[53] Hachenberg J., Bedorf D., Samwer K., Richert R., Kahl A., Demetriou M. D., Johnson W. L.: Merging of the $\alpha$ and $\beta$ relaxations and aging via the Johari-Goldstein modes in rapidly quenched metallic glasses. Applied Physics Letters, 92, 131911/1-131911/3 (2008).

https://doi.org/10.1063/1.2903697

[54] Brás A. R., Viciosa M. T., Wang Y., Dionísio M., Mano J. F.: Crystallization of poly(L-lactic acid) probed with dielectric relaxation spectroscopy. Macromolecules, 39, 6513-20 (2006).

https://doi.org/10.1021/ma061148r

[55] Mackintosh A. R., Liggat J. J.: Dynamic mechanical analysis of poly(trimethylene terephthalate) - A comparison with poly(ethylene terephthalate) and poly(ethylene naphthalate). Journal of Applied Polymer Science, 92, 2791-2796 (2004).

https://doi.org/10.1002/app.20290

[56] Saiter J. M., Grenet J., Dargent E., Saiter A., Delbreilh L.: Glass transition temperature and value of the relaxation time at $T_{\mathrm{g}}$ in vitreous polymers. Macromolecular Symposia, 258, 152-161 (2007).

https://doi.org/10.1002/masy.200751217

[57] Puente J. A. S., Rijal B., Delbreilh L., Fatyeyeva K., Saiter A., Dargent E.: Segmental mobility and glass transition of poly(ethylene-vinyl acetate) copolymers: Is there a continuum in the dynamic glass transitions from PVAc to PE? Polymer, 76, 213-219 (2015). https://doi.org/10.1016/j.polymer.2015.09.007 
[58] Leonardi A., Dantras E., Dandurand J., Lacabanne C.: Dielectric relaxations in PEEK by combined dynamic dielectric spectroscopy and thermally stimulated current. Journal of Thermal Analysis and Calorimetry, 111, 807-814 (2013).

https://doi.org/10.1007/s10973-012-2548-3

[59] Angell C. A.: Spectroscopy simulation and scattering, and the medium range order problem in glass. Journal of Non-Crystalline Solids, 73, 1-17 (1985). https://doi.org/10.1016/0022-3093(85)90334-5

[60] Angell C. A.: Formation of glasses from liquids and biopolymers. Science, 267, 1924-1935 (1995).

https://doi.org/10.1126/science.267.5206.1924

[61] Bouthegourd E., Esposito A., Lourdin D., Saiter A., Saiter J. M.: Size of the cooperative rearranging regions vs. fragility in complex glassy systems: Influence of the structure and the molecular interactions. Physica B: Condensed Matter, 425, 83-89 (2013).

https://doi.org/10.1016/j.physb.2013.05.029

[62] Sasaki T., Ichimura M., Irie S.: Correlation between fragility and cooperativity in segmental dynamics of glass-forming para-substituted polystyrenes. Polymer Journal, 47, 687-694 (2015).

https://doi.org/10.1038/pj.2015.50

[63] Chua Y. Z., Schulz G., Shoifet E., Huth H., Zorn R., Scmelzer J. P., Schick C.: Glass transition cooperativity from broad band heat capacity spectroscopy. Colloid and Polymer Science, 292, 1-12 (2014).

https://doi.org/10.1007/s00396-014-3280-2
[64] Saiter A., Delbreilh L., Couderc H., Arabeche K., Schönhals A., Saiter J-M.: Temperature dependence of the characteristic length scale for glassy dynamics: Combination of dielectric and specific heat spectroscopy. Physical Review E, 81, 041805/1-041805/8 (2010). https://doi.org/10.1103/PhysRevE.81.041805

[65] Donth E.: The size of cooperatively rearranging regions at the glass transition. Journal of Non-Crystalline Solids, 53, 325-330 (1982). https://doi.org/10.1016/0022-3093(82)90089-8

[66] Fischer E. W., Donth E., Steffen W.: Temperature dependence of characteristic length for glass transition. Physical Review Letters, 68, 2344-2346 (1992).

https://doi.org/10.1103/PhysRevLett.68.2344

[67] Rijal B., Delbreilh L., Saiter A.: Dynamic heterogeneity and cooperative length scale at dynamic glass transition in glass forming liquids. Macromolecules, 48, 82198231 (2015).

https://doi.org/10.1021/acs.macromol.5b01152

[68] Hamonic F., Prevosto D., Dargent E., Saiter A.: Contribution of chain alignment and crystallization in the evolution of cooperativity in drawn polymers. Polymer, 55, 2882-2889 (2014).

https://doi.org/10.1016/j.polymer.2014.04.030 